\title{
PROCESSO DE INTEGRAÇĀO DOCENTE ASSISTENCIAL: ESPAÇO E MOVIMENTO POSSÍVEIS NA CONSTRUÇĀO DO SABER EM SAÚDE COLETIVA
}

\author{
Emiko Yoshikawa Egry * \\ Rosa Maria G.S. Fonseca * \\ Hisako Shima * \\ Maria Josefina Leuba Salum *
}

\begin{abstract}
RESUMO - O trabalho relata e discute a integração docente-assistencial como espaço privilegiado para a construção de um saber em saúde coletiva que articule o conhecimento oriundo da prática profissional com o gerado pela academia, rompendo a dicotomia saber/fazer.
\end{abstract}

\begin{abstract}
The authors report and discuss the teaching-service integration as a privileged space to framing of the public health knowledge. By this construction it has been achieved a greater approach between the academic knowledge and the knowledge emerged of the practice.
\end{abstract}

\section{INTRODUÇĀO}

A construção do saber em saúde na nossa sociedade vem, historicamente, caracterizandose pela desarticulação entre o saber acadêmico e aquele que emerge do exercício da prática assistencial. Esta desarticulação guarda relação com o distanciamento existente entre o trabalho intelectual e o trabalho manual, característica do modo de produção capitalista que predomina na atual formação social brasileira. Nesta forma de organização, onde a sociedade está estratificada em classes sociais, a produção de conhecimento e prestação de serviços atendem ao projeto polftico da classe dominante reiterando as condições de dominação desta sobre as classes dominadas 4 . Ainda, o conhecimento da totalidade do processo de trabalho é prerrogativa das classes dominantes enquanto que às classes dominadas cumpre a execução de tarefas parciais, manuais e simplificadas. Regida pelos pressupostos do racionalismo positivista, a própria construção do saber universaliza os homens negando a sua diferenciação social e imobilizando a realidade, ignorando a sua dinamicidade e historicidade.

Esta mesma concepção positivista que visualiza nos movimentos da natureza e da história, "uma perene repetição dos mesmos ciclos" ", acaba dando conta de manter a distância e a compartimentalidade das trajetórias que respondem pela evolução do saber acadêmico e daquele que se origina no processo de trabalho dos serviços, ou seja, na prática. Embora desarticuladas, elas têm eixos comuns, no sentido de que ambas reiteram e reproduzem intervenções que interessam à perpetuação da ideologia dominante. Do mesmo modo, se garante a dominação internacional, pois as teorias absolutistas, que se fundamentam em realidades sociais alienígenas, invadem e atropelam o movimento de reflexão e criação que ocorreria a partir da compreensão de cada realidade objetiva aproximável, quer seja no âmbito da Educação, quer seja no da Saúde.

$\mathrm{Na}$ enfermagem brasileira, o saber acadêmico também deriva de teorias que não contemplam a realidade social do pars, acentuando com isso o distanciamento entre a "academia" e o "serviço". Dessa maneira, o saber produzido na "academia" torna-se impossível de operacionalização, passando a existir concretamente apenas para um grupo social muito restrito, em geral constiturdo pelos enfermeiros ligados às instituiçōes de ensino de nível superior.

"O saber de enfermagem expresso por suas teorias pode ser uma proposta voltada mais para as dimensões cientificas desta prática sem contemplar a dimensão social, não levando em consideração as contradições tanto no interior do trabalho de enfermagem como as relacionadas à estrutura social"'.

No trabalho em saúde coletiva, a afirmação referida acima cabe quase integralmente. Nele,

\footnotetext{
* Professores Doutores do Departamento de Enfermagem em Saúde Coletiva da Escola de Enfermagem da Universidade de São Paulo. Membros do Grupo de Trabalho Integração Docente Assistencial EEUSP/Munić́pio de Taboão da Serra, SP. Brasil.
} 
as contradições, tanto internas quanto externas, são absolutamente desconsideradas, prevalecendo a percepção superficial designada como "relacionamento dificultoso" entre as instituições formadoras de recursos humanos e as prestadoras de assistência.

Visando a superação das questōes postas, o GT-IDA da EEUSP (*) vem, há 4 anos, implementando a IDA com o horizonte de, através dela, estar buscando a unicidade entre a teoria e a prática. A unicidade mencionada expressa-se na relação praxiológica entre o trabalho intelectual e o trabalho manual, entendendo que o espaço de construção do saber em Saúde Coletiva deve ser ocupado por todos aqueles que estão vinculados a essa área de conhecimento e de prática.

\section{ESPAÇO E O MOVIMENTO CON- CRETOS DE CONSTRUÇĀO DO SA- BER}

O Projeto de IDA tem como um dos seus espaços de atuação o Município de Taboão da Serra (PIDA-EE/TS) e o seu desenvolvimento é feito pelo conjunto de docentes do NACE: IDASC, alunos de graduação da EEUSP e equipe técnica das Unidades Básicas de Saúde (UBS) pertencentes à Divisão de Saúde daquele Município. Busca transformar a qualidade de assistência e de ensino em saúde coletiva tendo como pressupostos orientadores: a dinamicidade, a historicidade, a participação, a construção coletiva, o compromisso e o horizonte ${ }^{3}$.

A região alvo - Município de Taboão da Serra - distante cerca de $15 \mathrm{~km}$ da capital do Estado de São Paulo, compreende uma área de cerca de $22 \mathrm{~km}^{2} \mathrm{e}$, em 1989, sua população estimada era de 161.076 habitantes, com densidade populacional de 7.321,63 hab/ $\mathrm{km}^{24}$.

A economia do Município baseia-se, principalmente, na indústrịa e no setor serviços que cresce para dar apoio ao primeiro, inexistindo atividades econômicas do setor agrário.

EGRY, BERTOLOZZI, SHIMA ${ }^{3}$, analisando os dados da FUNDAP ${ }^{5}$ e de FONSECA ${ }^{4}$, relatam que a "população economicamente ativa, em 1980, foi estimada em $57,7 \%$ da população total, distribuŕda entre $67,6 \%$ de homens e $32,4 \%$ de mulheres. Os setores que empregavam maior número de mão-de-obra assalariada eram os da indústria de transformação e da prestação de serviços. Cabe destacar que neste último, a jornada de trabalho de cerca de 1/3 dos trabalhadores era superior a 48 horas semanais".

Quanto ao rendimento médio familiar, $47,9 \%$ da população recebia, em 1980, entre 2 a
5 salários mínimos e 25,2\% entre 5 a 10 . Para que se possa avaliar a dimensão da problemática, o salário mírimo situava-se, na época, em cerca de 50 dólares, quando o cálculo apresentado pelo DIEESE (Departamento de Estudos Intersindicais) demonstrava que o mínimo necessário para compor uma cesta básica de alimentos era da ordem de 200 dólares.

Taboão da Serra é dotado de uma rede pública de 10 pré-escolas, 2 escolas de 1 으 e 2 은 graus, além de cursos profissionalizantes. Em 1980, havia no Munićpio 77,6\% de alfabetizados e $22,4 \%$ de não alfabetizados.

A população do Município, preponderantemente jovem, como reflexo do que ocorre em todo o Brasil, apresentava proporção semelhante entre os sexos; era formada majoritariamente $(76,9 \%)$ por migrantes, provenientes de zona urbana, de outras cidades do estado de São Paulo, bem como de outros Estados do país.

Em relação às condições de habitação, havia no Município cerca de 28 núcleos favelados totalizando 1547 barracos, revelando um contingente significativo de pessoas que viviam em condições extremamente precárias no que se refere à estrutura física de moradia e que, via de regra, não contavam com equipamentos urbanos tais como rede de água e de esgoto, luz e coleta de lixo.

Dentro deste quadro, era de se esperar que as condições de saúde se revelassem comprometidas, segundo mostram os dados a seguir.

A mortalidade infantil se situava em um nível intermediário se comparado aos índices internacionais. O seu coeficiente, no ano de 1984, foi de $38,1 / \mathrm{mil}$ nascidos vivos, devido, principalmente, ao alto coeficiente de mortalidade infantil neonatal por deficiente atenção ao parto.

Em 1986, havia no Munić́pio apenas 6 Unidades Básicas de Saúde (UBS) de caráter público, enquanto as instituições privadas eram representadas por 10 clínicas ambulatoriais, uma clínica de internação e 2 hospitais, os quais mantinham convênio com o serviço público ${ }^{4}$.

Inserido neste espaço, desenvolveu-se o diagnóstico interventivo da realidade da prática assistencial nas UNSs, como parte integrante das atividades da IDA no Múnicípio, que possibilitou problematizar a assistência à saúde é propor intervenções.

Entende-se por diagnóstico interventivo, um processo de conhecimento da realidade no qual $o$ ato de conhecer, por si só, introduz questões que torna diferenciada sua apreensão, por provocar questionamentos e pequenas mudanças quantitativas, não estruturais. A reflexão gerada pelos questionamentos impulsiona 0 processo de transformação.

(*) Atualmente, Núcleo de Apoio às Atividades de Cultura e Extensão Universitária: IDA em Saúde Coletiva (NACE: IDASC).

10 R. Bras. Enferm., Brasília, 45 (1): 9-14, jan./mar. 1992 
A apreciação do documento UNIVERSIDADE $^{9}$ onde estão expostas a referida problematização $e$ as proposições para a consecução da finalidade desta IDA (Anexos I e II), permite verificar a urgência de construção do saber assentada nas condições concretas da prática assistencial. O proprio documento aponta, ainda, o caminho e o processo que poderiam ser adotados, ou seja, o movimento praxiológico de congnição/ação do conjunto dos integrantes da IDA, apoiados no processo de progressivo domf́nio, a partir da compreensão dos elementos componentes do exercício laboral, do proximal ao distal, numa perspectiva de visualização totalizante. Desta forma, pela práxis, o saber emerge na transformação da realidade objetiva $\left({ }^{*}\right)$, em virtude da relação concreta teoriaprática estabelecida pelo conjunto dos professores,alunos,profissionais, ocupacionais e clientela,mediante a reflexão crítica sobre as questões que surgem no processo de ensino-aprendizagem e da assistência em saúde coletiva.

Segundo VASQUES"1, a práxis pode ser tanto reiterativa quanto reflexiva (transformadora), entendendo-se que as intervenções quantitativas, contribuem, pela sua acumulação gradativa, para transformações qualitativamente significativas da realidade objetiva.

Desse modo, as atividades da IDA, desde o seu início, vinham sendo pautadas em proposições conjuntas de transformação, contrapondo-se à unilateralidade, tanto do lado do "academicismo" como do "praticismo". Mesmo as ações desenvolvidas pelos integrantes da Escola de Enfermagem nas UBSs foram reiterativas no primeiro momento, reproduzindo as condições assistenciais existentes, ou seja, assemelhandose às atividades desenvolvidas pelos profissionais e ocupacionais, mesmo que com qualidade diferenciada. A partir do diagnóstico interventivo realizado para se tomar contato mais estreito com as condições assistenciais das UBSs, todas as proposições visando a melhoria da qualidade da assistência só foram implementadas a partir da sua assunção pelo conjunto de integrantes da IDA.

QUEIROZ, EGRY ${ }^{8}$, adaptando para a enfermagem a proposição de BREILH, GRAN$\mathrm{DA}^{2}$, referem que tal realidade objetiva deve ser aproximada nas suas três dimensões: a dimensão estrutural, que se refere aos processos mais gerais da sociedade, relativos ao desenvolvimento da capacidade produtiva e das relações de produção, da formação econômica e social e das formas político-ideológicas derivadas; a dimensão particular, que compreende os processos de reprodução social manifestos nos perfis epidemiológicos de classe, integrados pelo perfil reprodutivo de classe e perfil saúde-doença e formas especiais de prática e ideologia em saúde; a dimensāo singular, formada pelos processos individuais dos agentes sociais, dados pelas condições de consumo-trabalho individual e pelas formas de participação individual de organização e consciência.

$O$ processo de transformação, segundo QUEIROZ, EGRY ${ }^{8}$ deve, além da compreensão dos pressupostos e conceitos, articular as várias fases em movimentos espirais de captação, interpretação, intervenção e reinterpretação da realidade objetiva, de tal sorte que as fases percorridas sejam interpenetrantes.

Desta forma, a partir de aproximações sucessivas e gradativas da realidade objetiva, agindo e repensando sobre esta ação, ou seja, indo da prática à teoria e desta retornando à prática, num movimento dialético, foi garantida a relação entre o saber acadêmico e o saber gerado a partir da prática, construindo, desta forma, o saber em saúde coletiva. Assim, concebe-se a IDA não apenas enquanto estratégia de ação, mas enquanto referencial teórico-metodológico orientador do processo ${ }^{10}$.

\section{CONCLUSĀO}

A construção do saber em saúde coletiva é prerrogativa de todos os que estão vinculados a esta área de conhecimento e de prática. Entretanto, permanece em nossa sociedade a clara divisão entre o "saber acadêmico" e o saber criado a partir das necessidades da prática quotidiana. Em contraposição a esta divisão buscou-se, através do PIDA-EE/TS construir um saber enraizado na realidade assistencial. Este projeto, por ser um processo que conduz à crescente articulação interinstitucional e interpessoal, e ainda, por privilegiar a clientela como elemento essencial do conjunto dos envolvidos, possibilitou o espaço para a criação do conhecimento em saúde coletiva, através da reflexão crítica sobre a realidade objetiva do processo saúde-doença e do processo ensino-aprendizagem, socialmente determinados, nas suas três dimensões: estrutural, particular e singular. Tal realidade foi sucessivamente aproximada, captando-a, interpretando-a, intervindo sobre ela e reinterpretando a intervenção realizada, num contínuo movimento de (re) aproximação, constituindo-se num espaço que vem consolidando a construção do saber em saúde coletiva, através da práxis reflexiva e criadora.

(*) A realidade objetiva $\varepsilon$ compreendida, segundo Lenin (HAHN e KOSING, 1983), como sendo aquela que tem a propriedade de existir independentemente $\mathrm{e}$ fora da consciência humana. 


\section{REFERÊNCIAS BIBLIOGRÁFICAS}

1 ALMEIDA, M.C.P. de, ROCHA, J.S.Y. O saber de enfermagem e sua dimensão prática. São Paulo: Cortez, 1986.

2 BREILH, J., GRANDA, E. Saúde na sociedade: guia pedagógico sobre um novo enfoque do método epidemiológico. São Paulo: Instituto de Saúde/ABRASCO, 1986.

3 EGRY, E.Y., BER TOLOZZI, M.R., SHIMA, H. Integração docente-assistencial: a transformação da qualidade do ensino e da assistência em saúde coletiva através da condução praxiológica. Rev. Esc. Enf. USP. v.25, n. 2, p.169-176, ago., 1991.

4 FONSECA, R.M.G.S. da. Mulher, reprodução biológica e classe social: a compreensão do nexo coesivo através do estudo dialético do perfil reprodutivo biológico de mulheres atendidas nas Unidades Básicas de Saúde. São Paulo, 1990. (Tese-Doutorado) Escola de Enfermagem Universidade de São Paulo.

5 FUNDAÇĀO DO DESENVOLVIMENTO ADMINISTRA IIVO. - FUNDAP. Diagnóstico das condiçöes de saúde da região de Itapecerica da Serra. São Paulo, 1985. (mimeografado).
6 HAHN, E. , KOSING, A. A filisofia marxista-lenista: curso básico, Lisboa: Avante, 1983.

7 HENRIQUES, S.B. A ciência e a filosofia. Ci. e Cult . São Paulo, v.33, n. 2, p.198-212, fev. 1981.

8 QUEIROZ, V.M., EGRY, E.Y.B ases metodológicas para a assistencia de enfermagem fundamentada no materialismo histórico e dialético. \& 'v. Bras. Enf., v.4l, n. 1, p.26-33, 1988:

9 UNIVERSIDADE DE SĀO PAULO. Escola de Enfermagem. Projeto de integração docente assistencial Escola de Enfermagem da Universidade de São Paulo - Munictpio de Taboão da Serra: Documento de Proposta Conjunta de Trabalho. São Paulo, 1988. (mimeografado).

10 UNIVERSIDADE DE SĀO PAULO. Escola de Enfermagem. Departamento de Enfermagem em Saúde Coletiva. Integração docente-assistencial como referencial teórico-metodológico para o ensino e a pesquisa da assistência de enfermagem em Saúde Coletiva. (Relatório Preliminar de Pesquisa). São Paulo, 1989/90.

11 VASQUEZ, A.S. Filosofia da próxis. Rio de Janeiro: Paz e Terra, 1977.

\section{ANEXO I}

\section{ASSISTÊnCIA À SAÚdE EM TABOĀo DA SERRA (SP): PROBLEMATIZAÇĀo}

1) A política de Saúde do Munić́pio de Taboão da Serra retrata a ideologia contida na atual Política Nacional de Saúde, tanto no nível do discurso quanto da prática: as Instituições de Saúde, desarticuladas em sua organização, detêm a centralização das decisões a respeito da formulação e desenvolvimento dos seus programas e não existe a adoção de uma filosofia de atenção à saúde coletiva, ainda que venha sendo rediscutida a sua prática assistencial. Os programas desenvolvidos têm muito mais cunho de resolução pragmática das questões estreitas de doença e não do processo saúde/doença, questões essas calcadas na interpretação do fenômeno com. enfoque que, no máximo, é multicausal e individual, contrapondo-se à determinação social do processo e, por conseguinte, do coletivo.

2) A existência da clara explicitação da filosofia de assistência à saúde no Munićpío de Taboão da Serra, gera uma falsa autonomia dos dirigentes e dos praticantes das ações assistenciais na prestação dos serviços de saúde reafirmando com isso, ora posturas autoritárias frente à questão, ora "laissez-faire", centradas na maioria das vezes em decisões pessoais a críticas de interpretação da realidade de saúde.

3) A diferenciação dos recursos humanos e materiais dispostos em cada unidade básica de saúde, demonstra valores institucionais diferenciados, privilegiando algumas unidades de saúde (e não de determinadas classes sociais) em detrimento de outras. Assim é que, ao contrário do que ocorre com os Centros de Saúde Integração, não se dotam de recursos os Postos de Atendimento Sanitário (PAS) que surgem a partir de legítimas reivindicações populares, o que provoca um questionamento sobre as razỗes dessa diferenciação tão notória.

4) As ações de saúde das unidades são exclusivamente intramuros, não havendo, ainda, a organização sistematizada de outras, extra-muros, impedindo que as unidades assumam um caráter dinâmico de intervenção real na saúde, limitando-se à solução de queixas individuais descobertas a partir da demanda restrita aos programas oferecidos. Além disso, pelo caráter assistencialista que o desenvolvimento dos programas vem assumindo, a saúde não é encarada, na maioria das vezes, enquanto questão a ser trabalhada de forma reflexiva, o que impede a clientela de interpretar de forma real os seus agravos de saúde.

5) Os serviços de saúde consideram a comunidade como uma somatória de indivíduos, não reconhecendo que ela se organiza em uma estrutura social classista. Neste momento, o que se pode observar são apenas articulações para tentar ouvir as reivindicações da comunidade, mas não existem trabalhos efetivos envolvendo-a como um todo.

6) Não existe uma política clara de desenvolvimento de recursos humanos em saúde, portanto não 
existe um sistema organizado de supervisão, capacitação e reciclagem tanto dos profissionais como dos ocupacionais. As atividades que se desenvolvem nesse sentido são individualizadas e tal desenvolvimento se dá a partir de interesses pessoais. Carece-se também de um único e claro sistema de avaliação da atuação no trabalho; a avaliação que vem sendo realizada hoje, tem o sentido de promover, na maioria das vezes, cobranças de quantidade produzida ao invés de qualidade das intervenções.

7) Com raras exceções, a postura profissional em relação à clientela é bastante autoritária, de um modo impedindo o compartilhamento do saber e a conseqüente reflexão sobre as condições de saúde da clientela e, de outro, "empurrando" a adoção de valores das classes sociais dominantes e por isso mesmo, instrumentos de dominação (de higiene, de ascetismo, de conformismo) que são externos aos valores das classes sociais na qual está inserida a clientela.

8) As ações de saúde desenvolvidas são repetitivas (reiterativas) e até mecânicas, revelando por si só uma consciência ingênua na tomada da realidade; não há, portanto, reflexões críticas a respeito de todas as condutas e conduções, realizadas unilateralmente.

9) Os programas revelam a reiteração da opressão da classe dominada, primeiro, pelo cumprimento ingênuo e reflexivo deles e, segundo, por conter medidas paliativas de clara manutenção da dife-

renciação social, haja visto a distribuição de alimentos, por exemplo, o Programa de Suplementação Alimentar (PSA).

10) Há por parte dos profissionais de saúde e também dos ocupacionais a percepção de "universalidade" da comunidade ou falsa igualdade dentro da pobreza, não existindo a visualização da estrutura de classe (dos assistenciais e da clientela), de sua inserção no sistema produtivo, suas contradições e antagonismos.

11) Mais do que transparente a hegemonia do trabalho médico, absoluta nas unidades básicas, é a hegemonia do saber baseado nas acepções técnico-positivistas e no domínio ou detenção delas. A enfermagem, como corpo de conhecimentos e habilidades especf́ficas que visa a transformação da saúde, sequer é mencionada claramente no Modelo Assistencial; além disso, sua prática nada revela de transformadora.

12) Inexiste, nas unidades de saúde, uma filosofia de assistência de enfermagem, e até mesmo de "modelos assistenciais" e a categoria desenvolve o seu trabalho na esteira das decisões do profissional médico. A assistência de enfermagem prestada, em sua maioria, forma um conjunto desarticulado de ações que não chegam a propósito algum pela falta de horizontes explícitos a serem alcançados. Além disso, as ações ou procedimentos desenvolvidos carecem de revisão de sua qualidade técnica. $\mathrm{O}$ papel do profissional enfermeiro é descrito de forma tênue e sua prática revela posturas muito mais de administração burocrática de recursos humanos e materiais do que a administração de assistência à saúde e de assistência de enfermagem. Ainda, acresce-se o fato de os enfermeiros estarem assumindo a responsabilidade total na capacitação e reciclagem de pessoal auxiliar, cujo trabalho é raramente compartilhado de forma sistematizada com outros profissionais, com um sério agravante: a categoria é numericamente insignificante em comparação com outros profissionais; às suas ações assistenciais não $\varepsilon$ dado espaço e crédito, nem institucional e nem da própria categoria, tornando-se, então pouco expressiva a sua capacidade assistencial e sua contribuição na transformação efetiva da saúde da clientela. Esta situação tranformar-se-á, à medida em que se imponha o cunho assistencial direto por parte dos enfermeiros, cuja avaliação não deve ser tomada apenas por medidas quantitativas de "quantos clientes pôde se livrar hoje" com a chamada resolutividade . Esta resolutividade, vem permeando a falsa concepção de que se consegue encerrar a questão da determinação social do processo saúde-doença em simples poder unilateral rfgido e seguro de prática assistencial médico-terapêutica. Ela não se encerra, também como falsamente se coloca, na simplificação do que é complexo por não entender a estrutura desta complexidade e nem tampouco na redução do humano ao biológico; na interpretação de saúde como a falta de doença aparente ou diagnosticável; e na individualização do fenômeno que contraria a interpretação coletiva do mesmo.

13) Por fim, como causa e consequência das situações descritas, os programas (teóricos e práticos) estão à margem das reais necessidades de saúde da clientela que as unidades básicas pretendem atender, necessidades estas, que não devem ser interpretadas como estáticas, porém dinâmicas, compreendidas na historicidade de seu movimento.

Fonte: UNIVERSIDADE DE SAO PAULO. Projeto de Integração Docente-Assistencial da Escola de Enfermagem da USP (PIDA): Proposta de trabalho em Taboão da Serra. São Paulo, 1987/1988 (mimeografado). 


\section{ANEXO II \\ ASSISTÊNCIA À SAƯDE EM TABOĀO DA SERRA (SP): PROPOSTAS DE INTERVENÇĀO}

1) Conceptualização a cerca de temáticas chaves que explicitem a filosofia para o trabalho coletivo na área de saúde. Refere-se à proposição do marco conceitual contendo a clara tradução do significado de temas como: processo saúde-doença, saúde coletiva, assistência à saúde coletiva, enfermagem, educação, sociedade, homem e trabalho.

2) Instrumentação da equipe de saúde, alunos e docentes quanto à interpretação de fenômenos ligados à saúde dentro da ótica de determinação social do processo saúde e doença.

3) Aproximação gradativa e sistematizadora, fundamentada cientificamente, das duas realidades neste momento dicotomizadas: a real situação de saúde das comunidades e a assistência à saúde oferecida pelo sistema, por meio de diagnóstico que permita conhecer a saúde de diferentes classes sociais, seus estratos e frações.

4) Reorientação gradativa dos programas locais de saúde à luz do diagnóstico mencionado anteriormente.

5) Estabelecimento de processo que garanta a avaliação dos programas de saúde e ao mesmo tempo assegure aderência às necessidades de saúde da população.

6) Desencadeamento consciente de processo que garanta a participação da população em todos os momentos de forma a construir em conjunto a história da transformação da saúde.

7) Coordenação e articulação inter e intra institucional que viabilize a consecução dos projetos e programas assegurando a cadência de seu desenvolvimento.

8) Desenvolvimento da capacidade assistencial do enfermeiro pela implantação de programas assistenciais em nível de indivíduos, famnias, grupos e coletividade, embasados em referencial teórico e criterios de complexidade das necessidades assistenciais formuladas err. conjunto (prestador de assistência e clientela).

9) Atuação multiprofissional nas ações de saúde e divisão técnica do trabalho tendo em vista a capacitação técnico-científica e política do profissional e ocupacional, bem como a qualidade mínima (perfil) requerida para a atuação, constrúfda em conjunto e reorientada no sentido de transformação contínua.

10) Produção de conhecimentos científicos embasados em pesquisas operacionais e a divulgação destes conhecimentos assegurando sistema de troca, atualização e re-situação teórico-prática.

11) Definição de uma política de desenvolvimento de recursos humanos e estabelecimento de programas compatíveis, contemplando a formulação de:

- perfil existente e esperado dos profissionais e ocupacionais;

- sistema de seleção baseado no perfil;

- sistematização da avaliação e supervisão de pessoal;

- desenvolvimento de sistema de educação continuada, abrangendo a Pós-Graduação sensu lato e sensu strictu

12) Continuidade do desenvolvimento de programas de ensino de enfermagem em nível de graduação voltadas para a saúde coletiva, visualizando as dimensões estrutural, particular e singular: avaliação sistematizada destes programas e redirecionamento à luz das transformações oriundas da prática.

13)Reorientação do currŕculo vigente de enfermagem em nível de graduação na Escola de Enfermagem da USP subsidiadas pela transformação do perfil do profissional enfermeiro decorrentes de sua prática reflexiva e criadora.

14) Busca de estratégias para a transformação do currículo mínimo de enfermagem em nivel nacional aproximando cada vez mais o perfil desse profissional, emanado da prática aderente, às reais necessidades de saúde da população.

15) Estabelecimento de estrutura organizacional que garanta a coordenação, articulação e sistema de informação.

16) Proposição de ações de saúde extra muros ampliando a clientela no sentido de abarcar toda a população do Munić́pio de forma diferenciada de acordo com as prioridades visualizadas quando da interpretação dessas necessidades.

Fonte: UNIVERSIDADE DE SĀO PAULO. Projeto de Integração Docente-Assistencial da Escola de Enfermagem da USP (PIDA): Proposta de trabalho em Taboão da Serra. São Paulo, 1987/1988 (mimeografado). 